\title{
Vitamin D status of pregnant women and their infants in South India: VIPIS study
}

\author{
Preethi Navaneethan ${ }^{1 *}$, Thenmozhi Mani², Pradita Shrestha ${ }^{3}$, Annie Regi ${ }^{1}$, \\ Niranjan Thomas ${ }^{3}$, Anna Simon ${ }^{4}$
}

\begin{abstract}
${ }^{1}$ Department of Obstetrics and Gynecology, Unit III, ${ }^{2}$ Department of Biostatistics, ${ }^{3}$ Department of Neonatology, ${ }^{4}$ Department of Paediatrics, Unit I, Christian Medical College Hospital, Vellore, Tamil Nadu, India
\end{abstract}

Received: 15 May 2019

Accepted: 05 June 2019

*Correspondence:

Dr. Preethi Navaneethan,

E-mail: rnpreethi@yahoo.co.in

Copyright: (C) the author(s), publisher and licensee Medip Academy. This is an open-access article distributed under the terms of the Creative Commons Attribution Non-Commercial License, which permits unrestricted non-commercial use, distribution, and reproduction in any medium, provided the original work is properly cited.

\begin{abstract}
Background: Aim was to estimate the prevalence of vitamin D deficiency in pregnant women and their infants and to analyse the effect of maternal vitamin D deficiency on the infant.

Methods: A prospective study was done in the Department of Obstetrics and Neonatology in a tertiary centre in South India with 150 women seen in the antenatal clinic after 36 weeks of pregnancy were recruited. Serum vitamin D levels were obtained. Babies were followed up and sampled once between 10 and 20 weeks of age for vitamin D, calcium, phosphate and alkaline phosphatase. Vitamin D levels less than $20 \mathrm{ng} / \mathrm{ml}$ was considered as deficiency. Analysis of the data was done using SPSS 16.0 version.

Results: Vitamin D deficiency was seen in $64.8 \%$ of the pregnant women. Follow up of 76 babies showed vitamin D deficiency in $72.6 \%$ infants. Significantly high levels of alkaline phosphatase were noted in infants who were born to mothers with vitamin D deficiency, which indicates risk of developing bone disease.

Conclusions: This study highlights the high prevalence of Vitamin D deficiency in pregnant women and their infants in South India in a region with abundant sunshine. This study also emphasises treating vitamin D deficiency in pregnancy to reduce the risk of developing rickets in infancy.
\end{abstract}

Keywords: Infants, Hypovitaminosis, Prevalence, Pregnancy, South India, Vitamin D

\section{INTRODUCTION}

Vitamin D is an essential nutrient which is crucial for bone growth and mineralisation through its action on the metabolism of calcium and phosphorus. ${ }^{1}$ Research over the past decade has shown association between low vitamin D levels and cardiovascular, respiratory illness and altered glucose homeostasis. ${ }^{2}$ Vitamin D deficiency in pregnancy can be linked to adverse outcomes including pre-eclampsia, gestational diabetes, caesarean section, growth restriction and low vitamin D levels in infancy. ${ }^{3-5}$
Vitamin D deficiency is defined as levels less than $20 \mathrm{ng} / \mathrm{ml}$ as per the Institute of Medicine (IOM) and the endocrine society. ${ }^{6}$ Value between 21-29 $\mathrm{ng} / \mathrm{ml}$ of vitamin D is considered as insufficiency. Recent studies have identified Vitamin D deficiency as a global problem, with high prevalence of vitamin D levels less than $10 \mathrm{ng} / \mathrm{ml}$ in the Asian and Middle eastern countries. ${ }^{7}$ Prevalence of $95-97 \%$ has been reported in the studies done in North India. ${ }^{8}$ Current guidelines from WHO does not recommend vitamin $\mathrm{D}$ supplementation to improve maternal and perinatal outcomes but suggest 
supplementation of 200 IU per day in those with documented vitamin D deficiency. ${ }^{9}$

Aim was to estimate the prevalence of vitamin D deficiency in pregnant women and their infants in South India. The secondary objectives, were to assess the correlation between vitamin D deficiency and maternal factors, such as mother's parity, social factors (community, average time outdoors, dietary pattern, current vitamin D supplementation, BMI), mode of delivery, neonatal outcomes and to identify the effects of maternal vitamin D deficiency on the infant.

\section{METHODS}

This prospective cohort study was done in the Department of Obstetrics, Neonatology and Paediatrics in a tertiary centre in South India. The study was approved by the IRB and ethics committee. Pregnant women with singleton pregnancy after 36 weeks of gestation who were seen in the antenatal clinic were invited to participate in the study. The nature of the study was explained and an informed written consent was obtained. The study was carried out between April 2014 and October 2015.

The exclusion criteria were pregnancy complicated by diabetes, hypertension, chronic kidney disease and multiple pregnancies. With a relative precision of $10 \%$, confidence level of $95 \%$ and expectant prevalence of $72 \%$ vitamin D deficiency, based on studies done in North India, the sample size was calculated as 150 participants. $^{10}$ The details including obstetric score, occupational and educational status, parity, area of residence, religious background including using burqa (religious body cover), dietary history and sunlight exposure history were obtained.

Body mass index was calculated and skin tone measurement done using Fitzpatrick skin type Chart measurement. The skin colour was checked in the exposed side of the hand and categorised accordingly. Venous sample for serum vitamin D levels were obtained in a clotted tube at the time of recruitment. 25- $\mathrm{OH}$ Vitamin D levels were measured by the electro chemiluminescence immunoassay (ECLIA- Roche E170 immunoassay system). The measurement range of the assay was 3.0 to $70 \mathrm{ng} / \mathrm{ml}$. Vitamin D level of less than $20 \mathrm{ng} / \mathrm{ml}$ was taken as deficiency.

The delivery details including gestation at delivery, onset of labour and mode of delivery, intrapartum and postpartum complications were recorded. The baby details and neonatal events were also obtained. The babies were followed up between 10-20 weeks of age when the details including length, weight, feeding status, supplements and hospital admissions were obtained and the blood samples for vitamin D, calcium, phosphate and alkaline phosphatase were taken. Serum vitamin D levels less than $20 \mathrm{ng} / \mathrm{ml}$ was taken as deficiency. The infant was also examined for features of rickets by the paediatrician. Serum calcium of $9-11 \mathrm{mg} \%$, phosphate of $4-6.6 \mathrm{mg} \%$ and alkaline phosphate of $150-420 \mathrm{U} / \mathrm{L}$ were taken as normal.

\section{Statistical analysis}

Descriptive statistics was used, such as number and percentage for categorical variable and Mean and SD or as median with inter quartile range (IQR) for all the continuous variables. Histogram was done for continuous variables to study the distribution. When the histogram suggested normal distribution, independent t-test was applied, and if the distribution was non-normal, MannWhitney U test was used to compare between groups. Chi-square test was used for association between deficiency and other variables. $P$ value at $5 \%$ level significance was considered as statistical significance. Analysis was done using SPSS software 16.0 versions.

\section{RESULTS}

150 women were recruited in the study after informed written consent. Vitamin D results were unavailable in 5 pregnant women. Hence, a total of 145 women were included in the study. Three women were lost to follow up and did not come for the delivery in our hospital. The mean age of the pregnant women was 27.41 years.

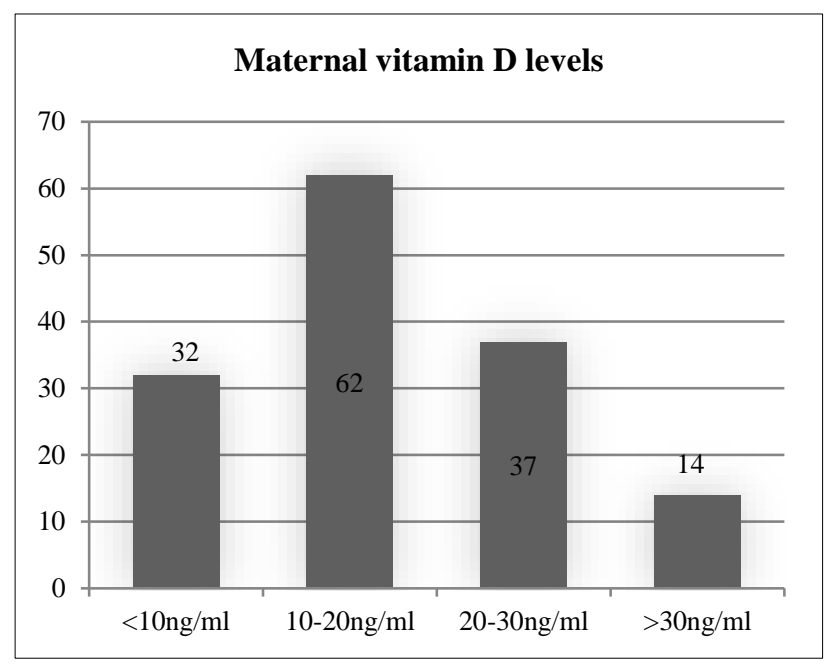

Figure 1: Categorisation of maternal vitamin D levels.

Table 1 shows the general characteristics of the antenatal women recruited in the study. Majority of the women were from Vellore (75.2\%) where the study was conducted. Most of the women in the study were not employed (78.6\%), Hindu by religion (86.2\%), Fitzpatrick skin tone IV $(77.2 \%)$ and of normal BMI (51.7\%).

Out of the 142 women who delivered in our hospital, 76 babies were followed up between 10-20 weeks of age (Mean 11.75 \pm 3.5 weeks), out of which 3 vitamin D samples were insufficient for analysis. Figure 1 shows the distribution of vitamin $\mathrm{D}$ levels in the pregnant women. 
Vitamin D deficiency defined as $25(\mathrm{OH})$ vitamin D levels less than 20ng/ml was identified in $64.8 \% \quad(\mathrm{n}=94)$ pregnant women out of which vitamin D levels of less than $10 \mathrm{ng} / \mathrm{ml}$ were noted in $22.4 \%(\mathrm{n}=32)$. Among the 73 infant samples that were analysed, $72.6 \%(n=53)$ infants had levels less than $20 \mathrm{ng} / \mathrm{ml}$. There was no evidence of clinical rickets in any of the infants.

Table 1: Maternal demographic characteristics.

\begin{tabular}{|c|c|c|}
\hline Characteristics & Numbers (n=145) & Percentage $(\%)$ \\
\hline \multicolumn{3}{|l|}{ Area of residence } \\
\hline Vellore & 109 & 75.2 \\
\hline Rest of Tamil Nadu & 32 & 22.1 \\
\hline Andhra Pradesh & 4 & 2.8 \\
\hline \multicolumn{3}{|l|}{ Occupation } \\
\hline Housewife & 114 & 78.6 \\
\hline Clerical work & 23 & 15.8 \\
\hline Labourer & 5 & 3.4 \\
\hline Professional & 3 & 2.2 \\
\hline \multicolumn{3}{|l|}{ Obstetric score } \\
\hline Primigravida & 70 & 48.3 \\
\hline Multigravida & 75 & 51.7 \\
\hline \multicolumn{3}{|c|}{ Gestation at recruitment } \\
\hline $36+0$ to $36+6$ weeks & 20 & 13.8 \\
\hline $37+0$ to $37+6$ weeks & 37 & 25.5 \\
\hline $38+0$ to $38+6$ weeks & 43 & 29.7 \\
\hline $39+0$ to $39+6$ weeks & 29 & 20.0 \\
\hline $40+0$ to $40+6$ weeks & 16 & 11.0 \\
\hline \multicolumn{3}{|l|}{ BMI } \\
\hline Underweight & 5 & 3.4 \\
\hline Normal & 75 & 51.7 \\
\hline Overweight & 56 & 38.6 \\
\hline Obese & 9 & 6 \\
\hline \multicolumn{3}{|l|}{ Religion } \\
\hline Christian & 4 & 2.8 \\
\hline Hindu & 125 & 86.2 \\
\hline Muslim & 16 & 11 \\
\hline \multicolumn{3}{|c|}{ Burqa (Religious head and body covering) } \\
\hline Yes & 15 & 10.0 \\
\hline No & 130 & 90.0 \\
\hline \multicolumn{3}{|l|}{ Milk intake } \\
\hline Less than $500 \mathrm{ml} /$ day & 128 & 88.3 \\
\hline More than $500 \mathrm{ml} /$ day & 17 & 11.7 \\
\hline \multicolumn{3}{|c|}{ Skin tone (Fitzpatrick classification) } \\
\hline Type 3 & 20 & 13.8 \\
\hline Type 4 & 112 & 77.2 \\
\hline Type 5 & 13 & 9.0 \\
\hline
\end{tabular}

Induction was done for various reasons in $53.8 \%(\mathrm{n}=78)$ of the women while $43.4 \% \quad(n=64)$ of the pregnant women went into labour spontaneously. Around 72\% $(n=106)$ delivered vaginally out of which instrumental delivery was required in $13 \%(n=20)$.

The remaining $24.8 \%$ of the women had caesarean section for various obstetric causes.
Table 2 shows the association between various factors and maternal vitamin D levels. No significant association was identified on the vitamin D levels based on the occupation, educational qualification, BMI, religious background and skin tone. The average hours of sunlight exposure among those with vitamin D deficiency was 3.6 hours/week and those with normal vitamin D levels were 6.2 hours/week which was statistically significant ( $p$ value 0.002 ). 
Table 2: Association between risk factors and maternal vitamin D deficiency.

\begin{tabular}{|c|c|c|c|}
\hline Characteristics & $\begin{array}{l}\text { Normal Vitamin D } \mathbf{n}=\mathbf{5 1} \\
(\%) \text { Mean } \pm \text { SD }\end{array}$ & $\begin{array}{l}\text { Vitamin D deficiency } n=94 \\
(\%) \text { Mean } \pm \text { SD }\end{array}$ & P value \\
\hline \multicolumn{4}{|l|}{ Occupation } \\
\hline Housewife & $43(37.7)$ & $71(62.3)$ & 0.676 \\
\hline Office work & $6(27.3)$ & $16(72.7)$ & \\
\hline Labourer & $1(16.7)$ & $5(83.3)$ & \\
\hline Professional & $1(33.3)$ & $2(66.7)$ & \\
\hline \multicolumn{4}{|l|}{ BMI } \\
\hline Underweight & $1(20.0)$ & $4(80.0)$ & \multirow{3}{*}{0.624} \\
\hline Normal & $29(38.7)$ & $46(61.3)$ & \\
\hline Overweight & $21(32.3)$ & $44(67.7)$ & \\
\hline Sunlight exposure & & & 0.002 \\
\hline (hours/week) & $6.23 \pm 6.72$ & $3.6 \pm 3.98$ & \\
\hline (Median(IQR)) & $4(2.7)$ & $2(1.4)$ & \\
\hline \multicolumn{4}{|l|}{ Skin tone } \\
\hline Type III & $7(35.0)$ & $13(65.0)$ & \multirow{3}{*}{0.748} \\
\hline Type IV & $41(36.6)$ & $71(63.4)$ & \\
\hline Type V & $3(23.1)$ & $10(76.9)$ & \\
\hline \multicolumn{4}{|l|}{ Religion } \\
\hline Christian & $1(25.0)$ & $3(75.0)$ & \multirow{3}{*}{0.375} \\
\hline Hindu & $47(37.6)$ & $78(62.4)$ & \\
\hline Muslim & $3(18.8)$ & $13(81.3)$ & \\
\hline \multicolumn{4}{|l|}{ Qualification } \\
\hline Primary/Sec school & $19(45.2)$ & $23(54.8)$ & \multirow{3}{*}{0.261} \\
\hline Graduate & $19(30.2)$ & $44(69.8)$ & \\
\hline Post graduate/Professional & $13(32.5)$ & $27(67.5)$ & \\
\hline \multicolumn{4}{|l|}{ Mode of delivery } \\
\hline Normal & $25(29.1)$ & $61(70.9)$ & \multirow{3}{*}{0.205} \\
\hline Instrumental & $8(42.1)$ & $11(57.9)$ & \\
\hline Caesarean section & $16(44.4)$ & $20(55.6)$ & \\
\hline
\end{tabular}

Table 3 shows the mean vitamin D levels in the mother and the infants. The mean vitamin $\mathrm{D}$ level in the pregnant women was $17.47 \pm 8.4 \mathrm{ng} / \mathrm{ml} \quad(\mathrm{n}=145)$. Among the 73 infants, the mean vitamin D level was $14.56 \pm 9.13 \mathrm{ng} / \mathrm{ml}$. The mean serum calcium was $10.03 \pm 0.36 \mathrm{mg} \%$, serum phosphate was $5.684 \pm 0.68 \mathrm{mg} \%$ and alkaline phosphatase was $323.3 \pm 117.5 \mathrm{U} / \mathrm{L}$.
Table 3: Mean vitamin D levels in mother and infants $(\mathrm{ng} / \mathrm{ml})$.

\begin{tabular}{|ll|}
\hline Serum Vitamin D levels & Mean \pm SD in $\mathrm{ng} / \mathrm{ml}$ \\
\hline Maternal vitamin D levels & $17.47 \pm 8.4$ \\
\hline Infant vitamin D levels & $14.56 \pm 9.13$ \\
\hline
\end{tabular}

Table 4: Comparison between maternal vitamin D levels and baby outcomes.

\begin{tabular}{|ll|ll|}
\hline Baby outcomes & $\begin{array}{l}\text { Maternal Vitamin D deficiency } \\
(\mathbf{n = 4 5})\end{array}$ & $\begin{array}{l}\text { Normal Vitamin D } \\
(\mathbf{n = 2 8})\end{array}$ & P value \\
\hline Birth weight & $3018.5 \pm 379.5$ & $3115.1 \pm 410.4$ & 0.178 \\
\hline SGA & $21(22.6)$ & $13(26.5)$ & 0.604 \\
\hline $\begin{array}{l}\text { Infant vitamin D levels } \\
\text { vitamin D deficiency }\end{array}$ & $37(82.2 \%)$ & $16(61.5 \%)$ & 0.0535 \\
\hline Alkaline phosphatase Mean \pm SD & $357.47 \pm 129.15$ & $275.71 \pm 79.57$ & 0.002 \\
\hline Elevated alkaline phosphatase & $13(28.9 \%)$ & $1(3.6 \%)$ & 0.007 \\
\hline
\end{tabular}


Table 4 shows association of maternal vitamin D deficiency and infant outcomes. The average birth weight was $3057.2 \pm 462.8 \mathrm{~g}$. There was no significant association between maternal vitamin $\mathrm{D}$ deficiency, birth weight and small for gestational age. Vitamin D deficiency was noted in $82.2 \%(n=37)$ of the infants born to mothers with vitamin $\mathrm{D}$ deficiency and $61.8 \%(\mathrm{n}=16)$ of infants born to mothers with normal vitamin D levels which showed borderline significance with $\mathrm{p}$ value of 0.053 . Alkaline phosphatase levels were significantly high in the infants born to mothers with vitamin $\mathrm{D}$ deficiency $(\mathrm{n}=13$, $29.5 \%$ ) when compared to the infants whose mothers had normal Vitamin D levels $(n=1,3.6 \%)$ with a $p$ value of 0.007 . Serum calcium levels were normal in all the infants. Alkaline phosphatase was elevated in $20.8 \%$ $(n=11)$ babies with vitamin $D$ deficiency and $16.7 \%$ $(n=3)$ babies with normal Vitamin D levels ( $p$ value $0.69)$.

\section{DISCUSSION}

Cutaneous vitamin D3 (cholecalciferol) along with those derived from animal sources and Vitamin D2 (ergocalciferol) derived from plants are hydroxylated in the liver to $25(\mathrm{OH})$ cholecalciferol. This is further hydroxylated into the most active form 1, 25(OH) cholecalciferol) in the kidneys. ${ }^{1}$ Since $25(\mathrm{OH})$ cholecalciferol is the most stable form with long half-life of 15 hours, it is used as the biomarker for vitamin D levels. ${ }^{11} 25(\mathrm{OH})$ vitamin $\mathrm{D}$, the active form of vitamin $\mathrm{D}$ crosses the placenta and previous studies have shown the cord vitamin D levels was equal or up to $20 \%$ lower of the maternal vitamin D levels. ${ }^{12}$

This study found the prevalence of vitamin D deficiency in pregnant women of our population in Vellore (latitude $12^{\circ} 56^{\prime} \mathrm{N}$, longitude $79^{\circ} 8^{\prime} \mathrm{E}$ ), South India to be more than $60 \%$ in spite of abundant sunshine. Veena et al found similar rates of vitamin $\mathrm{D}$ deficiency in pregnant women from South India. ${ }^{13}$ However, studies from North India have shown higher rates. ${ }^{8,14}$ According to the study done by Arora et al, the prevalence was $95.5 \%$ and similar rate of $93.5 \%$ was reported by Sharma et al. This is probably due to the difference in the amount of sunshine between the two parts of the country.

Vitamin D deficiency is attributed to various risk factors including ethnic origin, economic status, skin tone, food intake, maternal weight, duration and timing of sunlight exposure. ${ }^{6,15}$ However, the differences between the two groups did not show statistical significance in our study except for the duration of sunlight exposure. This is probably due to the smaller sample size.

Research on the association between vitamin D deficiency and low birth weight has produced conflicting results. Review done by Thorne-Lyman showed that majority of studies showed no association while larger study by Leffelaar et al, showed significant association. ${ }^{16,17}$ Our study did not show difference in birth weight between those with normal Vitamin D and those with deficiency and no association between vitamin $\mathrm{D}$ deficiency and small for gestational age.

We noted significantly high levels of alkaline phosphatase in infants at 10-20 weeks of age who were born to mothers with Vitamin D deficiency which indicates risk of developing bone disease. This suggests that maternal vitamin $\mathrm{D}$ deficiency is an independent risk factor for developing rickets in infants less than 6 months of age.

Vitamin D deficiency in the neonate is a global problem due to the high prevalence of maternal vitamin D deficiency. In this study, the vitamin D deficiency was noted in $72.6 \%$ of the infants who were followed up between 10-20 weeks of age. Recent study in Japan by Nakano et al also showed similar results with vitamin D levels less than $20 \mathrm{ng} / \mathrm{ml}$ in $75 \%$ of the infants. ${ }^{18}$ Study on healthy breastfed infants in Delhi (North India) showed a prevalence of $86.5 \% .^{19}$

Food fortification and targeted Vitamin D supplementation policies are recommended when the public health convention or the disease burden is $>20 \%$. ${ }^{1}$ Our study adds evidence of high prevalence of vitamin D deficiency in the pregnant women and their infants in South India as seen in other studies from North of India. Indian Academy of Paediatrics has recommended routine vitamin D supplementation of 400 IU/day till 1 year of age to prevent rickets. ${ }^{20}$ Currently, national guidelines on routine vitamin $\mathrm{D}$ supplementation in pregnancy is not available in India.

\section{CONCLUSION}

This study highlights the need for identification of vitamin $\mathrm{D}$ deficiency in pregnancy and in infancy and need for a national guideline on vitamin $D$ supplementation and treatment in pregnancy. This study also emphasis treating vitamin D deficiency in pregnancy to reduce the risk of developing rickets in infancy. Further studies are required to identify the risk reduction by correcting maternal vitamin $\mathrm{D}$ levels. Improving awareness among the public and health care professionals, food fortification, targeted national programme on vitamin $\mathrm{D}$ supplementation can help in reducing the prevalence of vitamin $\mathrm{D}$ deficiency in pregnancy.

\section{ACKNOWLEDGMENTS}

Authors would like to thank (Late) Prof Mark Steinhoff for his contribution to the conception of the study and for his involvement in improving the analysis of the data. We also thank Prof Steinhoff, Global Health Centre, Cincinnati for funding the study. Authors acknowledge Dr Pamela Christudoss, Department of Clinical Biochemistry for her involvement in laboratory analysis of Vitamin D. 
Funding: No funding sources

Conflict of interest: None declared

Ethical approval: The study was approved by the Institutional Ethics Committee

\section{REFERENCES}

1. Roth DE, Abrams SA, Aloia J, Bergeron G, Bourassa $\mathrm{MW}$, Brown $\mathrm{KH}$, et al. Global prevalence and disease burden of vitamin D deficiency: a roadmap for action in low- and middle-income countries. Ann N Y Acad Sci. 2018;1430(1):44-79.

2. El-Fakhri N, McDevitt H, Shaikh MG, Halsey C, Ahmed SF. Vitamin D and its effects on glucose homeostasis, cardiovascular function and immune function. Horm Res Paediatr. 2014;81(6):363-78.

3. Wagner CL, Hollis BW. The Implications of Vitamin $\mathrm{D}$ status during pregnancy on mother and her developing child. Front Endocrinol. 2018:9. Available at: https://www.ncbi.nlm.nih.gov/pmc/ articles/PMC6127214/

4. Amraei M, Mohamadpour S, Sayehmiri K, Mousavi SF, Shirzadpour E, Moayeri A. Effects of Vitamin D deficiency on incidence risk of gestational diabetes mellitus: a systematic review and meta-analysis. Front Endocrinol. 2018;9:7.

5. O'Callaghan KM, Kiely M. Systematic Review of Vitamin D and hypertensive disorders of pregnancy. Nutrients. 2018;10(3).

6. Holick MF, Binkley NC, Bischoff-Ferrari HA, Gordon CM, Hanley DA, Heaney RP, et al. Evaluation, treatment, and prevention of vitamin $\mathrm{d}$ deficiency: an endocrine society clinical practice guideline. J Clin Endocrinol Metab. 2011. Available at: http://press.endocrine.org/doi/10.1210/jc.20110385.

7. Saraf R, Morton SMB, Camargo CA, Grant CC. Global summary of maternal and newborn vitamin D status - a systematic review. Matern Child Nutr. 2015;12(4):647-68.

8. Arora S, Goel P, Chawla D, Huria A, Arya A. Vitamin D status in mothers and their newborns and its association with pregnancy outcomes: experience from a tertiary care center in Northern India. J Obstet Gynaecol India. 2018;68(5):389-93.

9. WHO, Vitamin D supplementation during pregnancy. WHO. Available at: http://www.who.int/elena/titles/guidance_summaries/ vitamind_supp_pregnancy/en/.

10. Agarwal N, Faridi MMA, Aggarwal A, Singh O. Vitamin D Status of term exclusively breastfed infants and their mothers from India. Acta Paediatr Oslo Nor. 1992;99(11):1671-4.

11. Hong-Bi S, Yin X, Xiaowu Y, Ying W, Yang X, Ting $C$, et al. High prevalence of vitamin D deficiency in pregnant women and its relationship with adverse pregnancy outcomes in Guizhou, China. J Int Med Res. 2018;0300060518781477.

12. Kovacs CS. Vitamin D in pregnancy and lactation: maternal, fetal, and neonatal outcomes from human and animal studies. Am J Clin Nutr. 2008;88(2):520S-528S.

13. Veena SR, Krishnaveni GV, Srinivasan K, Thajna KP, Hegde BG, Gale CR, et al. Association between maternal vitamin $\mathrm{D}$ status during pregnancy and offspring cognitive function during childhood and adolescence. Asia Pac J Clin Nutr. 2017;26(3):43849.

14. Sharma S, Kumar A, Prasad S, Sharma S. Current Scenario of Vitamin D Status During Pregnancy in North Indian Population. J Obstet Gynaecol India. 2016;66(2):93-100.

15. Bukhary NBI, Isa ZM, Shamsuddin K, Lin KG, Mahdy ZA, Hassan $\mathrm{H}$, et al. Risk factors for antenatal hypovitaminosis D in an urban district in Malaysia. BMC Pregnancy Childbirth. 2016. Available at: https://www.ncbi.nlm.nih.gov/pmc/ articles/PMC4944244/.

16. Leffelaar ER, Vrijkotte TGM, Eijsden M van. Maternal early pregnancy vitamin D status in relation to fetal and neonatal growth: results of the multiethnic Amsterdam Born Children and their Development cohort. Br J Nutr. 2010;104(1):108-17.

17. Thorne-Lyman A, Fawzi WW. Vitamin D during pregnancy and maternal, neonatal and infant health outcomes: a systematic review and meta-analysis. Paediatr Perinat Epidemiol. 2012;26(1). Available at: https://www.ncbi.nlm.nih.gov/pmc/articles/PMC384 $3348 /$.

18. Nakano S, Suzuki M, Minowa K, Hirai S, Takubo N, Sakamoto Y, et al. Current Vitamin D status in healthy Japanese infants and young children. J Nutr Sci Vitaminol (Tokyo). 2018;64(2):99-105.

19. Jain V, Gupta N, Kalaivani M, Jain A, Sinha A, Agarwal R. Vitamin D deficiency in healthy breastfed term infants at 3 months and their mothers in India: Seasonal variation and determinants. Indian J Med Res. 2011;133(3):267-73.

20. Khadilkar A, Khadilkar V, Chinnappa J, Rathi N, Khadgawat R. From Indian Academy of Pediatrics 'Guideline for Vitamin D and Calcium in Children' Committee. Prevention and Treatment of Vitamin D and Calcium Deficiency in Children and Adolescents: Indian Academy of Pediatrics (IAP) Guidelines. Indian Pediatr. 2017;54(7):567-73.

Cite this article as: Navaneethan $\mathrm{P}$, Mani $\mathrm{T}$, Shrestha P, Regi A, Thomas N, Simon A. Vitamin D status of pregnant women and their infants in South India: VIPIS study. Int J Reprod Contracept Obstet Gynecol 2019;8:2820-5. 